\title{
Book review: Postwachstumsgeographien: Raumbezüge diverser und alternativer Ökonomien
}

\author{
Jevgeniy Bluwstein \\ Department of Geosciences, University of Fribourg, Chemin du Musée 4, 1700 Fribourg, Switzerland \\ Correspondence: Jevgeniy Bluwstein (jevgeniy.bluwstein@unifr.ch)
}

Published: 31 October 2020

Lange, B., Hülz, M., Schmid, B., and Schulz, C.: Postwachstumsgeographien: Raumbezüge diverser und alternativer Ökonomien, transcript Verlag, Bielefeld, 447 pp., ISBN 978-3-8376-5180-5, EUR 29,00, 2020.

This edited volume is a timely contribution to debates on geographies of degrowth, a rapidly growing field of academic research and grassroots activism and action. The anthology is structured along four themes - perspectives, possibilities, conflicts and spaces for action. Each of these themes offers a mix of empirically grounded analytical contributions as well as concrete examples of degrowth initiatives in practice. Aspects such as work, leisure, consumption, production, social innovation, cooperation, creativity, entrepreneurship, care, housing, mobility, digitalization, arts, urban and rural development, and agriculture are covered from a geographies-of-degrowth perspective. The intention is to highlight already realized - although often overlooked, marginalized and informal - practices of degrowth and thereby to reclaim these aspects from a traditional growth-oriented approach in science and policy towards an institutionalized degrowth agenda. The authors also highlight how concrete examples - local practices of degrowth - are tied in with other scales, geographies and networks of decision-making, policy and politics.

The book experiments with an innovative format to connect scholarship on degrowth geographies and economies with degrowth practices and policymaking. Concrete examples and interviews provide further insights from the field of degrowth activism, research and practice. This mix of academic scholarship with attention to activism and practice of realizing and living degrowth will be of interest for geography students and teachers, activists, and policymakers in search for alternatives, new concepts and strategies to business-as-usual local and regional economic development.
Two important red threads run through the anthology. First, there is an ambition to highlight the spatiality in geographies of degrowth-oriented socioecological transitions, such as through attention to placemaking, networks, scales and territories. Here, a central aspiration is to shed light on how processes and strategies of degrowth can be rescaled and institutionalized. Second, case studies are used to highlight how concrete projects and initiatives - from urban planning to working, living, producing and consuming - are subjected to built-in growth imperatives while also having degrowth potential. Spaces for degrowth may already co-exist with spaces of inherent growth or can be created through a departure from and abandonment of growth imperatives.

The book's key objective is to invite planning sciences to take degrowth scholarship and practice more seriously. In the introductory chapter, the authors call for an uptake of degrowth as an object of research, activism and policymaking by planning sciences, beyond the usual core disciplines of (feminist) geography, ecological economics, political economy and ecology. The authors see the need for spatial and economic planners to engage in degrowth debates, concepts and practices when dealing with concrete and policy-relevant aspects such as land and agriculture, housing and work, sharing economies, and urban and rural development. Here, the authors challenge planners to critically reflect on their discipline's core concepts that are implicitly underpinned by an economic growth-oriented agenda (such as a focus on GDP, productivity, investment, innovation, economic actors and activities). However, the authors also see an opportunity in mobilizing concepts from planning sciences for a degrowth research and policy agenda.

The first theme of the book (perspectives) highlights how an explicit geography perspective can contribute to our understanding of degrowth practices, strategies and processes. What makes transformation a spatial practice and 
how are places reconfigured through socioecological transitions? How can we mobilize the analytics of space, place, network, territory and scale to make sense of sociospatial transformations? The second theme of the book (possibilities) focuses on concrete cases, actors and their perceptions of degrowth processes and transitions. Where and how is degrowth already a lived experience and practice? How does it co-exist, clash with, or reconfigure entrenched models of growth? What are the challenges in overcoming growthoriented ways of living, planning, working, producing and consuming? The third theme of the book (conflicts) illustrates some of the key tensions underpinning degrowth transitions, such as the role of finance, and the question of global uneven development. How can degrowth in the Global North be advanced in a globalized world economy that ties together spaces of uneven development and socioecological inequalities? How can marginalized and subaltern voices, knowledge and epistemology be included in degrowth transitions? How can colonial legacies be overcome in degrowth transitions? How do financial markets and financialization stand in the way of a just transition? What are the limits and promises of green and sustainable finance? The fourth and last theme of the book (spaces of action) asks how planners can learn from a geographical conceptualization and analysis of degrowth practices and challenges. Particular attention is given to the role of education in planning sciences, to the role of policies in advancing a degrowth perspective in and through urban and rural planning, and to the role of civil society in these processes of transition to alternative and diverse economies.
The book covers a lot of ground, and the four themes overlap in various ways. This is a strength of the collection, yet at times it also raises questions as to why a particular chapter is placed in one theme and not another. This conceptual, analytical and empirical diversity can also be challenging for critical geographers and political ecologists who may find some of the contributions lacking analytical depth or a critical perspective pertaining to key concepts such as sustainability, resilience, development, work, capital, transition or growth. Moreover, readers interested in exploring analytical and political tensions and contradictions between capitalism and degrowth may be disappointed, as these aspects have been hardly covered from a macroeconomic perspective. Nevertheless, this freely available (as a PDF) anthology is a valuable and timely addition to literature and debates on (de)growth and socioecological transitions. 